\title{
Does digital competence and occupational setting influence MOOC participation? Evidence from a cross-course survey
}

\author{
Jonatan Castaño-Muñoz ${ }^{1} \cdot$ Karel Kreijns $^{2}$ • \\ Marco Kalz ${ }^{2,3}$ (Dves Punie ${ }^{1}$
}

Published online: 18 October 2016

(c) The Author(s) 2016. This article is published with open access at Springerlink.com

\begin{abstract}
While MOOCs are recognized nowadays as a potential format for professional development and lifelong learning, little research has been conducted on the factors that influence MOOC participation of professionals and unemployed in MOOCs. Based on a framework developed earlier, we conducted a study, which focused on the influence of background variables such us digital competence, age, gender and educational level on MOOC participation. Occupational setting was considered as a moderator in the analysis of the impact of digital skills. Results of the study showed that MOOCs were an important tool for unemployed participants who were more likely to enroll in MOOCs than employed learners. MOOCs were also a way for workers who do not received employer support for other training activities to get professional development training. Results of the regression analysis
\end{abstract}

The paper is based on a conference paper presented during the Fourth European MOOCs Stakeholder Summit (eMOOCs2016).

The views expressed in this article are purely those of the authors and should not be regarded as the official position of the European Commission.

Marco Kalz

marco.kalz@ou.nl

Jonatan Castaño-Muñoz

jonatan.castano-munoz@ec.europa.eu

Karel Kreijns

karel.kreijns@ou.nl

Yves Punie

yves.punie@ec.europa.eu

1 Institute for Prospective Technological Studies, European Commission, Seville, Spain

2 Welten Institute, Open University of the Netherlands, Heerlen, Netherlands

3 Faculty of Management, Science and Technology, Open University of the Netherlands, Heerlen, Netherlands 
showed that a person's level of digital competence was an important predictor for enrolment in MOOCs and that specifically interaction skills were more important than information skills for participating in the MOOC context.

Keywords MOOCs · Open education · Professional development · Digital competence · Employer support

\section{Introduction}

The impact of professional development on the labour market has been widely analyzed in the literature (Jenkins et al. 2002; Card et al. 2010; Hällsten 2012; Jepsen and Montgomery 2012). Human capital theory states that the value of people's knowledge and competences declines with time. Therefore, lifelong learning is a key issue at a time when, due to fast socio-technological changes, workers need to update their skills throughout their working lives (Blanden et al. 2012; Castaño-Muñoz et al. 2013; Laal and Salamati 2011). In this context, lifelong learning has become an important aspect of many European educational policies (European Commission 2011).

Adult education and education for professionals needs to be adapted according to the needs of lifelong learners. Recent technological advancements can contribute to removing existing barriers to involvement in lifelong learning (Kalz 2015). Adult learners have different time constraints and learning expectations to traditional learners (Schuetze and Slowey 2002). Sometimes, previous experience allows adult learners to play an active role in planning their own learning to achieve personal or career-oriented goals (Falconer et al. 2013). MOOCs offer many new options for professional development and lifelong learning. Indeed, MOOCs provide access to open (higher) education for people who were previously denied this opportunity for financial reasons or because they lacked the necessary qualifications, or for other reasons. On the other hand, MOOCs can offer professionals a plethora of opportunities to acquire more knowledge or develop skills and competences related to their current jobs or they can help them to acquire new knowledge and skills they need to take other professional directions.

Although Open Education and MOOCs are recognized as offering opportunities for lifelong learning due to their flexibility, and the fact that they fit well with the concept of self-directed learning, there has been surprisingly little interest in analyzing their relationship with the labour market. The literature usually divides lifelong learning in three types: public programmes, on the job training, and formal accredited courses (Heckman and Smith 1999; Blanden et al. 2012). However, now that MOOC based learning has been added to the range of options it needs to be better studied and analyzed according to its impact.

Milligan and Littlejohn (2014) identified the benefits and challenges of professional learning MOOCs for health professionals. Their research showed that there was a mismatch between learners' initial learning intentions, which were linked to the challenges of their profession, and their behavior, which mainly consisted of the completion of activities that led directly to a certificate. 
Furthermore, they did not share experiences with each other or transfer their own learning to on-the-job practices. These results led the authors to report that there is still a need to explore how MOOCs should be designed for professional training.

Despite the design problems mentioned above, Zhenghao et al. (2015) reported from a survey they administered in 2014 that MOOCs may benefit learners' careers. The authors analyzed data of people who had completed MOOCs on the Coursera platform. They found that many of them (52\%) were looking for tangible career benefits (increasing their salaries, finding new jobs, or starting new businesses) and also intangible ones (being better equipped to do their current job, improving their chances of getting a new job). Moreover, their research showed that, in general, career benefits were more likely to be mentioned by individuals with high socioeconomic status (SES). Tangible career benefits, however, were referred to equally by individuals with both low and high SES. In addition, in developing countries respondents with low SES and education levels were significantly more likely to indicate tangible career benefits. Moving from workers' perspective employer's perspective, Radford et al. (2014) analyzed how human resource professionals in the USA perceive MOOCs. These researchers sent a questionnaire to a sample of 398 organizations in North Carolina and obtained responses from 103 employers. This low response rate and the self-selection of respondents could have generated a selection bias by over-representing companies which were more aware of MOOCs. The field work was carried out between November 2013 and January 2014 and the results revealed that MOOCs had reached nearly half the employers in the sample. Though only a few companies used MOOCs actively for recruitment, two-thirds of the sample agreed that the fact that an applicant had taken job-related MOOC would positively influence their hiring decisions. Approximately $7 \%$ of the surveyed organizations had used MOOCs for professional development and most of these were part of the public administration. According to this study, this could change because $83 \%$ of employers were using, considering using, or could see their organization using MOOCs for professional development in the future.

The studies presented above showed that there are tangible career benefits for individuals participating in MOOCs and that MOOCs are also recognized already by some organizations for their potential for professional development. However, there is little empirical research available about factors that influence participation by professionals and the unemployed in MOOCs. Our study aimed to fill this gap by providing a better understanding of how different levels of digital competence and different occupational settings interact and affect the level of participation in MOOCs. The study investigated the following research questions:

- What are the characteristics, (age, gender, educational level, occupational setting, digital competence and past experience with MOOCs) of those individuals who actively participate in MOOCs and are employed for wages or unemployed but looking for a job?

- To what extent was past participation in MOOCs influenced by the occupational of the participants?

- To what extent was past participation in MOOCs influenced by the digital competence of participants? 
- To what extent does the impact of digital competence on MOOC participation vary according to the occupational setting of the individual?

In a cross-provider survey of five MOOCs in 2014 we collected data from participants on these variables.

\section{Theoretical framework}

This paper uses initial data from the MOOCKnowledge project, in which data from participants of MOOCs was collected in order to find out more about how learners perceived open online courses. In the current study, only European participants were considered. The MOOCKnowledge project adopted a theoretical framework we developed and described earlier (Kalz et al. 2015). The research framework was based on the reasoned action approach (RAA) by Fishbein and Ajzen (2010) and self-determination theory (SDT) developed by Ryan and Deci (2000). These two frameworks provide the basis for predicting human social behaviour and consist of background factors (e.g., socio-economic status) that affect different variables and directly influence the behavioural intention to participate in MOOCs. The framework operates with intentions and behaviour and suggests that an "intention-behavior-gap" can occur in MOOCs because they are open and offer a nonformal learning context. Participants who enroll in MOOCs do so with different intentions and the fulfilment of these depends on a variety of external (=environmental) or internal (=psychosocial) factors.

In the specific study we are discussing in this paper, we focused on several distal variables - these variables are depicted in Fig. 1 as variables at the individual level. Figure 2 shows the conceptual model we used. In order to study the relationships

distal variables

\begin{tabular}{|l|}
\hline individual level \\
- demographics \\
- social economic status \\
- past experience with enrolling \\
in MOOCs and completing them \\
- skills and abilities \\
- instrumental skills \\
- information literacy \\
- online communication skills \\
\hline environmental level \\
1. professional environment \\
- organization type \\
- leadership \\
- learning climate \\
- social influence \\
- descriptive norm \\
- social support \\
2. personal environment \\
- houshold composition \\
- social influence \\
- descriptive norm \\
- social support \\
\hline task level \\
- usefulness of the MOOCs \\
- usability \\
- utility \\
- quality of the MOOCs \\
- satisfaction with MOOCs \\
\hline
\end{tabular}

proximal variables

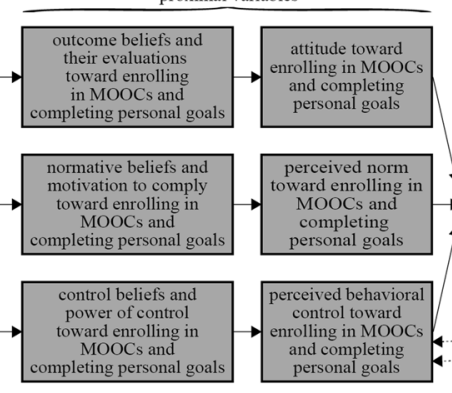

intention-behavior gap

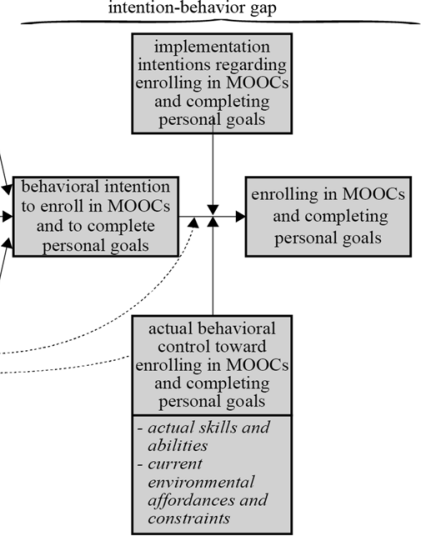

Fig. 1 MOOC research model (Kalz et al. 2015) 


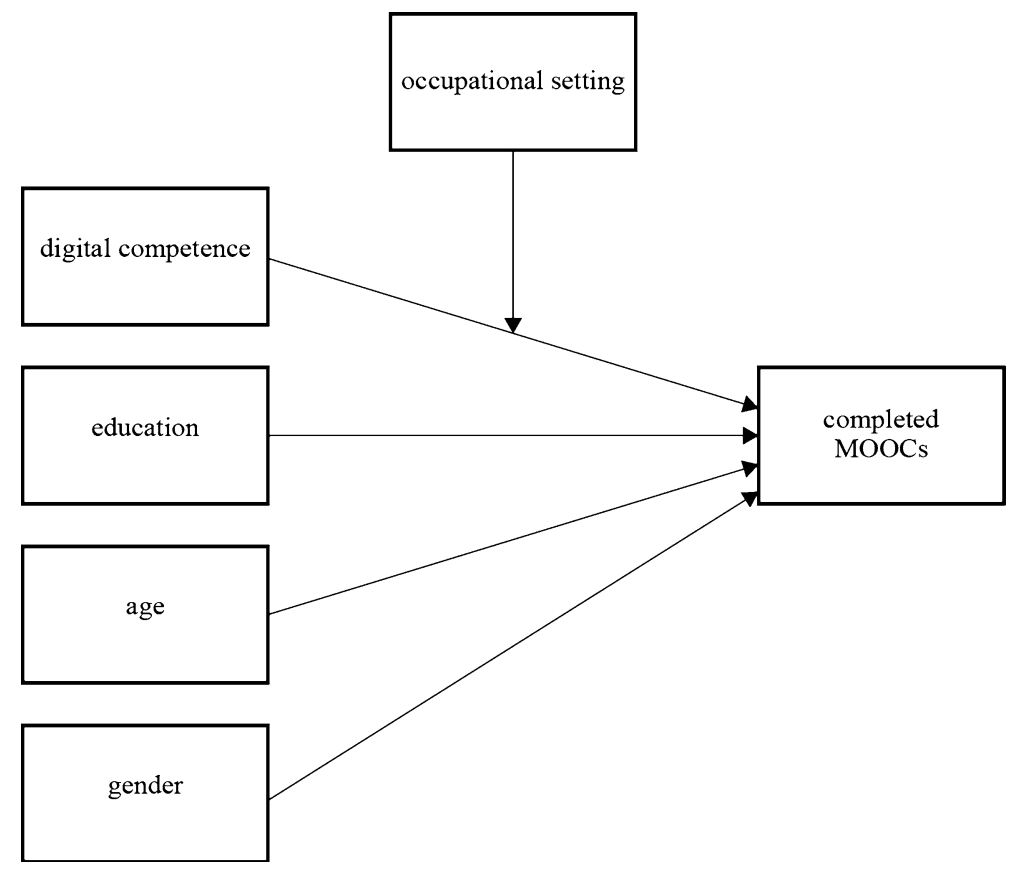

Fig. 2 Conceptual model of the current study

formulated in the research questions, we have analyzed gender, age, education and digital competence as background variables and occupational setting as a moderator variable of the impact of digital competence on the participation in MOOCs operationalized as the number of enrolled MOOCs.

\section{Method}

To obtain answers to our research questions, we conducted several analyses based on a dataset from a survey of participants in 5 different MOOCs: three Spanish MOOCs (business intelligence, test anxiety and entrepreneurship), one MOOC from an international project (Hands-on ICT) and one Dutch MOOC (blended learning). The data $(\mathrm{n}=3470)$ was collected via an online survey which was carried out between October 2014 and December 2014. Participation was voluntary and informed consent was obtained from participants. The Dutch MOOC attracted only few respondents because most of the participants had already filled in a course evaluation and our questionnaire was not available in Dutch.

In order to reduce the variability of different labour market contexts we focused on participants who were resident in the European Union. In addition, for the purpose of our analysis, we selected only participants who were either unemployed but looking for a job or employed for wages. This sample of interest was composed of 951 individuals. 
The first step of the analysis consisted of a univariate description of the survey respondents' characteristics. This allowed us to answer our first research question: "What are the characteristics, (age, gender, educational level. Occupational setting, digital competence and past experience with MOOCs) of those individuals who actively participate in MOOCs and are employed for wages or unemployed but looking for a job?".

The interpretation of these results should take into account the specific context and methods of this study. On the one hand, the fact that the majority of students came from Spain might have introduced a bias which may render the results less representative to other context with different socioeconomic conditions (e.g., lower unemployment rate). On the other hand, it has to be considered that survey respondents do not necessarily represent the totality of individuals enrolled in MOOCs. Nevertheless, participation in a survey is a good indicator of persistence and active participation (Evans et al. 2016) and works as a filter for our population of interest (active learners). In addition, the following considerations about the measurement of the variables presented can help to understand the study results better:

a. Educational level: In order to measure the educational level, in this study we used the educational levels taxonomy defined by the International Standard Classification of Education in 1997 (UNESCO 2006). However, due to the fact that MOOC takers usually have a high level of education, we decided to concentrate only on those respondents who had reached the second stage of tertiary education versus those who did not rather than examining all the educational levels of the respondents.

b. Occupational setting: In the context of this study occupational setting refers to employment situation (i.e. whether participants work for wages or are unemployed but looking for a job) along with two different support situations for employed participants (professional development is promoted vs. not promoted). In the questionnaire support by employers to professional development was differentiated into three types: (i) only encouragement, (ii) the second type was support in terms of time that otherwise would have been spent on work-related activities, and (iii) support in terms of cost compensation. In rare cases, support was other than the three types mentioned here was received. However, as only a small number of workers received support from their employers, we have aggregated all types of support into a dummy variable for analytical reasons. This variable divided the workers between those who receive support for professional development and those who do not receive it.

c. Digital competence: Due to the lack of an existing validated scale, we constructed a six item scale, which deals with information skills (three items) and interaction skills (three items), see Table 2 in the Results section. These competence areas have been identified earlier as most important in the MOOC context. Information skills refer to competences that are necessary for finding information on the internet and distinguishing if it is reliable or not. Interaction skills refers to competences related to the degree to which a learner can interact with technology-enhanced learning environments to collaborate with other 
learners. These two dimensions of the scale contain items that represent the basic skills required to follow MOOCs successfully. Principal Component Analysis (PCA) with orthogonal rotation was used to reduce the information of the original six items to these two dimensions and to estimate two independent scales that do not lead to collinearity problems. In the Results section we will present the items together with the factor loadings (Table 2) and will go more in depth about the construct validity of the digital competence scale.

d. Past experience with MOOCs: We collected information about two variables: the number of MOOCs participants had enrolled in the past and the number they had completed. Only participants who had enrolled in at least one MOOC in the past were asked this question. Therefore, with regard to the enrolled MOOC takers, we distinguished for comparability reasons between MOOC takers who had been enrolled in zero MOOCs and those who had been enrolled in one or more MOOCs.

In a second step, the analysis focused on how different levels of digital competence and different occupational settings interplay and impacted the level of participation on MOOCs (Research questions 2, 3 and 4). The number of MOOCs enrolled was used to measure MOOC participation. Enrolment in MOOCS is not the same as participation. A considerable number of learners enroll in a MOOC but then never start it. However, past enrolment in MOOCs works as a good proxy for MOOC participation. It seems logical that the more MOOCs a learner enrolled in the past the higher the possibility that they actively participated in them is. This is confirmed by the fact that the number of MOOCs a student enrolls in and the number of MOOCs she/he completes are highly correlated ${ }^{1}(\rho=0.84, p<0.001)$. In addition, focusing on the number of enrolled MOOCs allowed us to include in our analysis individuals who were participating for first when they responded to the questionnaire.

In order to answer our research questions, we estimated the number of MOOCs that students enrolled in (EM) as a function of a vector of:

a. Learners' socio-demographic characteristics: Age $(A)$ is a continuous variable and gender $(G)$ a nominal variable. Level of education differentiated among respondents who reached the second stage of tertiary education and those who did not reach this stage. The dummy variable $(E)$ represented this situation.

b. Occupational setting (OS). Occupational setting is a nominal variable containing 3 possible categories: unemployed but looking for a job (UN), worker without employer support (WnS) and worker with employer support (WS). This variable was split into dummy variables for inclusion in the regression.

c. Learner's Digital competence: Digital competence areas of interest were represented by two uncorrelated factors from PCA. Therefore, information (INF) and interaction (INT) areas were continuous variables.

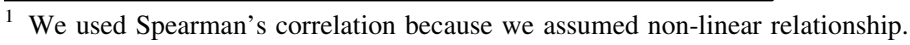


The number of MOOCs enrolled on in the past is a count variable and therefore a Poisson regression is needed to estimate it. In addition, in our model, occupational setting is seen as a moderator variable (Hayes 2013) of the effect of INF and INT on EM (See Fig. 3). We decided to replicate the Poisson regression (1) using interactions between variables and (2) not using them. Consequently, the statistical analysis done is described by the following basic equations:

$$
\begin{aligned}
\ln (E M)= & b_{0}+b_{1} A+b_{2} A^{2}+b_{3} G+b_{4} E+b_{6} I N F+b_{7} I N T+b_{51} W S+b_{52} W n S \\
& +b_{53} U N+\text { errorterm }
\end{aligned}
$$

$$
\begin{aligned}
\ln (E M)= & b_{0}+b_{1} A+b_{2} A^{2}+b_{3} G+b_{4} E+b_{6} I N F+b_{7} I N T \\
& +b_{51} W S+b_{51 \_6} W S * I N T+b_{51 \_7} W S * I N F \\
& +b_{52} W n S+b_{52 \_}{ }_{6} W n S * I N T+b_{52}{ }_{7} W S * I N F \\
& +b_{53} U N+b_{53 \_} U N * I N T+b_{53 \_} U N * I N F+\text { error term }
\end{aligned}
$$

Or

$$
\begin{aligned}
\ln (E M)= & b_{0}+b_{1} A+b_{2} A^{2}+b_{3} G+b_{4} E+b_{51} W S+b_{52} W n S+b_{53} U N \\
& +\left(b_{6}+b_{51}{ }_{6} W S+b_{52}{ }_{6} W n S+b_{53}{ }_{6} U N\right) I N T \\
& \left(b_{7}+b_{51 \_}{ }^{7} W S+b_{52}{ }_{7} W n S+b_{53}{ }_{7} U N\right) I N F+\text { error term }
\end{aligned}
$$

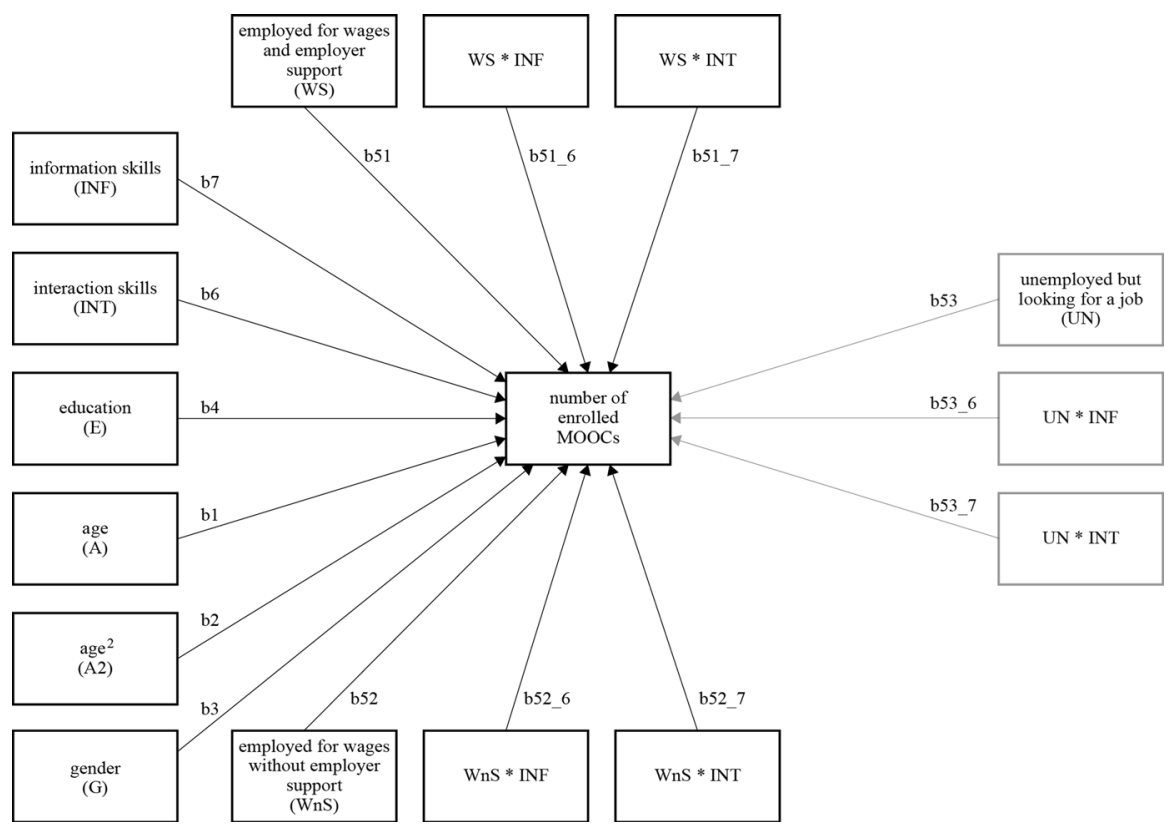

Fig. 3 Statistical model of the current study. Regression models did not include UN because it was selected as reference category. In order to show that, betas related to UN are greyed in the graph and equations 
In order to check the robustness of the models we decided to replicate these two basic equations using different sample combinations on the basis of the following criteria:

1. Using the full sample vs using a sample of respondents who declared they had experience in up to $30 \mathrm{MOOCs}$, and therefore excluding the higher extreme of this variable, and,

2. Using the full sample vs using a sample of respondents who had already participated in a MOOC before participating in the one where they responded the survey.

The eight resulting regression models were conducted using STATA software and its results are presented in the results section (Table 4).

On the light of the result of the regression analysis, we explored a possible cause of the difference in MOOC participation between workers witch employers support training activities and workers who do not have this support. In order to explore a possible substitution effect between MOOCs and non-MOOC training, we used two variables that measure the number of hours devoted on non-MOOC training during last month and week respectively. We performed a difference of means in this variables between the two groups of workers. Results are presented in the point "Influence of occupational setting on MOOC participation.

\section{Results}

In order to answer the research questions, we present the results in the same order that we posed them. Table 1 shows the demographics (gender, age and level of education) of the individuals per MOOC. Although the subpopulation of interest is $\mathrm{n}=951$, the number of respondents differ in the variable occupational setting due to no-response of some individuals.

Overall, the percentage of women who participated in the MOOCs included in the study is around $56 \%$. This is considerably higher than the 2:1 male to female rate found in some U.S studies (Glass et al. 2016). This finding could be explained by the fact that the MOOCs in our sample did not include the usual IT or engineering courses. The male-female ratio varies according to the topic of the MOOC. More women tend to participate in Hands-on ICT and test anxiety courses (over $70 \%$ ), whereas fewer participate in business intelligence and entrepreneurship courses (38 and $42 \%$ respectively).

The mean age of men and women in our population is similar $(\mathrm{M}=42.9 \mathrm{SD}=9$ and $\mathrm{M}=41.6 \mathrm{SD}=9.5$ respectively), the median age is 43 . These figures are higher than reported in other studies. For example, Ho et al. (2015) reported a median age of less than 30 years in Harvardx and MITx courses and Zhenghao et al. (2015) report a median age of 41 for Coursera MOOCs. Although longitudinal research suggested that the average age of MOOC learners is increasing, (Glass et al. 2016), the high mean age in our data may be caused by the fact that we were 
Table 1 Demographics and occupational status of the selected subsample

\begin{tabular}{|c|c|c|c|c|c|c|}
\hline & \multicolumn{5}{|l|}{ MOOCs } & \multirow[t]{2}{*}{ Total } \\
\hline & $\begin{array}{l}\text { Business } \\
\text { intelligence }\end{array}$ & $\begin{array}{l}\text { Hands-on } \\
\text { ICT }\end{array}$ & $\begin{array}{l}\text { Test } \\
\text { anxiety }\end{array}$ & $\begin{array}{l}\text { Blended } \\
\text { learning }\end{array}$ & Entrepreneurship & \\
\hline \multicolumn{7}{|c|}{ Gender $(\mathrm{n}=951)$} \\
\hline Male & 160 & 39 & 115 & 15 & 71 & 400 \\
\hline Female & 100 & 104 & 280 & 16 & 51 & 551 \\
\hline \multicolumn{7}{|c|}{$\operatorname{Age}^{\mathrm{a}}(\mathrm{n}=951)$} \\
\hline Male & $41.3(9.1)$ & $44.6(6.8)$ & $44.0(9.2)$ & $50.8(9.8)$ & $42.0(8.6)$ & $42.9(9)$ \\
\hline Female & $41.0(9.4)$ & $42.6(7.3)$ & $41.1(10.1)$ & $48.1(7.9)$ & $41.3(10.2)$ & $41.6(9.5)$ \\
\hline \multicolumn{7}{|c|}{ Education $(\mathrm{n}=951)$} \\
\hline \multicolumn{7}{|c|}{ Without 2nd stage of tertiary education } \\
\hline Male & 60 & 10 & 60 & 4 & 33 & 167 \\
\hline Female & 28 & 20 & 90 & 4 & 25 & 167 \\
\hline \multicolumn{7}{|c|}{ With 2nd stage of tertiary education } \\
\hline Male & 100 & 29 & 55 & 11 & 38 & 233 \\
\hline Female & 72 & 84 & 190 & 12 & 26 & 384 \\
\hline \multicolumn{7}{|c|}{ Occupational setting $(\mathrm{n}=815)$} \\
\hline \multicolumn{7}{|c|}{ Unemployed } \\
\hline Male & 33 & 2 & 33 & 2 & 34 & 104 \\
\hline Female & 27 & 6 & 121 & 1 & 30 & 185 \\
\hline \multicolumn{7}{|c|}{ Worker without support to professional development } \\
\hline Male & 63 & 16 & 54 & 1 & 21 & 155 \\
\hline Female & 46 & 39 & 108 & 5 & 13 & 211 \\
\hline \multicolumn{7}{|c|}{ Worker with support to professional development } \\
\hline Male & 24 & 12 & 13 & 8 & 8 & 65 \\
\hline Female & 12 & 43 & 26 & 8 & 6 & 95 \\
\hline
\end{tabular}

$\mathrm{n}$ respondents for each variable in parenthesis

${ }^{\text {a }} \mathrm{M}(\mathrm{SD})$

selecting only learners who were currently working or looking for a job, and excluding younger people such as students.

Unsurprisingly, the vast majority of our sample $(81 \%)$ have completed tertiary education and $65 \%$ have completed a second stage of tertiary education. (70\% of women and $58 \%$ of men). This is in line with the high educational levels reported in previous research on MOOCs (Ho et al. 2015).

Around one-third of our sample of interest (35\%) was unemployed but looking for a job and the rest $(65 \%)$ was employed. Among those individuals who were currently working only one-third $(30 \%)$ received employer support for professional development activities. The proportion of unemployed/employed for wages in our sample differed from the data available for the US context (Christensen et al. 2013) 


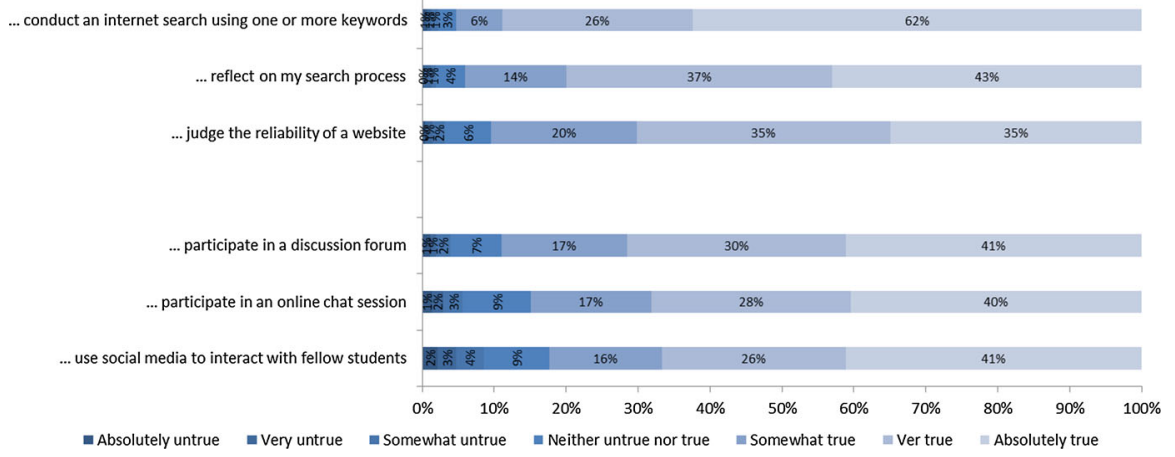

Fig. 4 Digital competence

where focusing only on the subsample of learners who were either unemployed or workers for wages, the proportion is $11 \%$ unemployed and $89 \%$ employed..

Figure 4 shows the means for each of the digital competence items. Unsurprisingly, the data showed that our survey respondent's digital competence level was high according to the criteria usually applied for measuring digital competence in the wider population.

The results of PCA carried out to reduce the information of the six items into two scales are shown in Table 2. The 2-factor solution fitted well with the measurement of our theoretical concepts (factor $1=$ information skills and factor $2=$ interaction skills) and met the basic statistical requirements: eigenvalues of the factors are higher than 1 and the two factors together explain $80 \%$ of the variance of the six original variables. These two factors will be used as variables in regression models which aim to answer aimed to respond to research questions 2, 3 and 4.

Finally, Table 3 depicts the average number of MOOCs participants were enrolled in the past and the average number of MOOCs they completed. For comparability and presentation reasons we distinguished between MOOC takers with or without previous experience in MOOCs. The majority of our respondents had followed one or several MOOCS. Only $19 \%$ were participating in a MOOC for the first time. The mean number of MOOCs taken by the learners with previous

Table 2 PCA for digital competences index: factor loadings with a 2-factor (rotated) solution

\begin{tabular}{llll}
\hline No. item & Item & $\begin{array}{l}\text { 2-factor solution (N of valid } \\
\text { observations }=741)\end{array}$ \\
\cline { 3 - 3 } & & Factor 1 & Factor 2 \\
\hline 1 & ...conduct an internet search using one or more keywords & 0.859 \\
2 & $\ldots$...judge the reliability of a website & 0.823 & \\
3 & ...reflect on my search process & 0.861 & 0.764 \\
4 & ...participate in a discussion forum & & 0.903 \\
5 & ...participate in an online chat session & & 0.881 \\
6 & ...use social media to interact with fellow students & & \\
\hline
\end{tabular}


Table 3 Average number of MOOCs enrolled and completed

\begin{tabular}{|c|c|c|c|c|c|c|}
\hline & \multicolumn{5}{|l|}{ MOOCs } & \multirow[t]{2}{*}{ Total } \\
\hline & $\begin{array}{l}\text { Business } \\
\text { intelligence }\end{array}$ & $\begin{array}{l}\text { Hands-on } \\
\text { ICT }\end{array}$ & $\begin{array}{l}\text { Test } \\
\text { anxiety }\end{array}$ & $\begin{array}{l}\text { Blended } \\
\text { learning }\end{array}$ & Entrepreneurship & \\
\hline \multicolumn{7}{|c|}{ Number MOOCs enrolled (all, $\mathrm{n}=849)^{\mathrm{a}}$} \\
\hline Male & $4.03(6.2)$ & $2.6(4.5)$ & $6.8(7.7)$ & $4.9(7.7)$ & $7(8.9)$ & $5.3(7.3)$ \\
\hline Female & $3.7(3.99)$ & $2.0(3.5)$ & $6(6.0)$ & $3.1(7.5)$ & $6.6(6.9)$ & $4.8(5.7)$ \\
\hline \multicolumn{7}{|c|}{ Number MOOCs enrolled (one or more MOOCs in the past, $n=687$ ) ${ }^{a}$} \\
\hline Male & $5.4(6.7)$ & $4.3(5.1)$ & $7.5(7.8)$ & $4.9(7.7)$ & $7.6(9.1)$ & $6.5(7.6)$ \\
\hline Female & $4.7(3.9)$ & $3.92(4.1)$ & $6.6(5.9)$ & $4.6(8.9)$ & $7.5(7.0)$ & $6.0(5.8)$ \\
\hline \multicolumn{7}{|c|}{ Number MOOCs completed in the past $(\mathrm{n}=687)^{\mathrm{a}}$} \\
\hline Male & $4.7(6.7)$ & $2.8(4.2)$ & $5.6(6.2)$ & $1.8(3.03)$ & $5.8(9.2)$ & $4.9(6.9)$ \\
\hline Female & $4.0(3.6)$ & $2.8(3.7)$ & $4.6(5.1)$ & $2.1(6.08)$ & $5.7(7.0)$ & $4.33(5.1)$ \\
\hline
\end{tabular}

${ }^{\mathrm{a}} \mathrm{M}(\mathrm{SD})$

experience with MOOCs was around 6 and most of them had taken more than one MOOC in the past. Participants enrolled on a mean of around 6 MOOCs and completed a mean of more than 4 .

\section{Influence of occupational setting on MOOC participation}

Our findings (see Table 4) showed that MOOCs were an important part of nonformal learning for individuals who were facing difficulties in the labour market. The unemployed in our sample tended to participate in MOOCs more than the employed, and indeed the estimates showed that this is one of the most important variables for predicting the number of MOOCs a learner will enroll in.

When we focus on workers, the regression models showed how those who have their employer support for professional development activities participated less in MOOCs than those who do not have this support. This was true in the models where all learners were included. In order to determine what the main cause for this was, we compared the level of participation in non-MOOC learning activities of the two groups. We focused on participation in the last month and last week. The results showed that the number of hours devoted to non-MOOC learning was higher for learners with employer support than the hours devoted by learners without support (mean $=5.9 \mathrm{~h} /$ week and 4.9/week, $\mathrm{t}=-1.7321 p=0.04$ and 25 and $19 \mathrm{~h} / \mathrm{month}$ $\mathrm{t}=-2.129 p=0.016$ respectively). This result supported the hypothesis that workers with employer support participate in MOOCs less often than those who have employer support because they participate more frequently in other training activities.

\section{Influence of digital competence on MOOC participation}

The level of digital competence in the areas measured played a key role in the decision to enrol on MOOCs. The results presented in Table 4 indicated that both information and interaction skills were important. However, our estimates for 
interactions skills were higher and more stable than those for information skills, revealing interaction as a key area of digital competence for MOOC participation. This result was consistent with previous research which showed how interaction skills were more important than information skills for taking advantage of and being successful in online courses (Bernard et al. 2009; Castaño-Muñoz et al. 2014).

\section{Impact of digital competence in different occupational settings}

When analyzing the interactions proposed in the model (models 2, 4, 6 and 8 in Table 4), the fact that occupational setting plays a moderator role of occupational setting in the effect of interaction skills was clear. The fact of being unemployed or employed with employer support to professional development maximized the impact of having good digital interaction skills. Therefore, unsupportive settings were hindering the possibilities of using communication competences for MOOC participation. This was especially relevant because as seen before communication skills were important determinants of participation in MOOCs.

On the other hand, the moderator role played by occupational setting in the effect of digital information competence was not stable among the proposed models. In the models where the whole population was included it seemed being occupied with support of the employer increased the effect of information competences. However, this relationship disappeared when we analyzed the regressions without including people who declared they had enrolled on more than 30 MOOCs. Indeed, in the regressions where we left out participants who were taking their first MOOC (models 7 and 8) the effect was reversed and negative. So our data did not allow to confirm that occupational setting plays a moderator role for information skills.

\section{Impact of other variables}

According to our estimates in Table 4, age played a positive role in MOOC enrolment. In addition, in the models where interactions were included a quadratic relationship was found which indicates that the positive effect on MOOC enrolment declined for older students. This relationship makes sense because young people tend to have more "fresh" knowledge and skills and need less up- or re-skilling. On the other hand, the quadratic relationship could be interpreted as a sign of older workers participating less in training activities simply because they had less careertime to benefit from the new skills acquired.

In all the proposed models women tended to participate in MOOCs less often than men. However, this trend was smaller in the models where extremes (people with more than 30 MOOCS) were eliminated, indicating that there were fewer women in the extreme end of the distribution. Finally, those respondents with the highest levels of education (second stage tertiary education) enrolled more often than those with first stage tertiary education. 


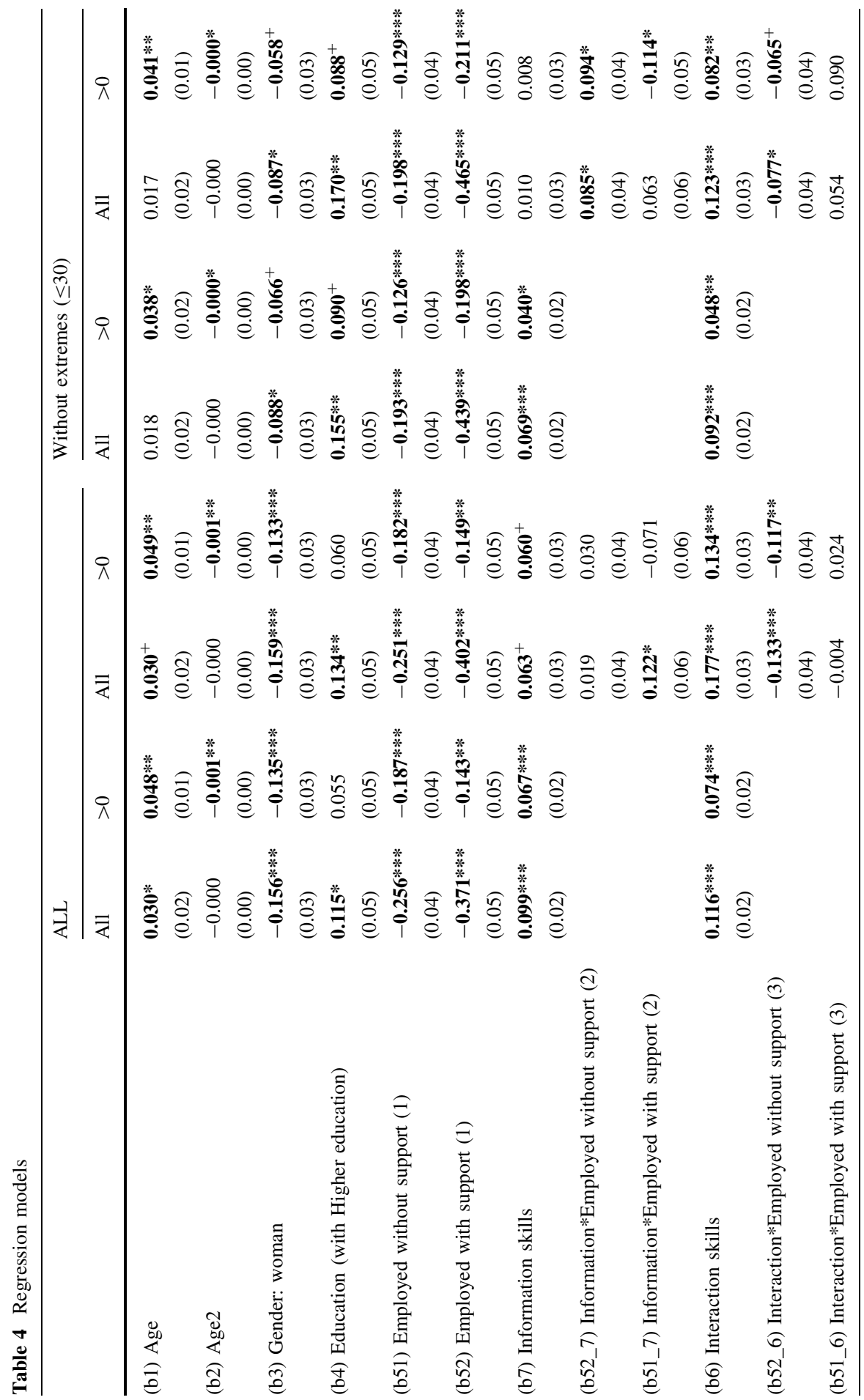




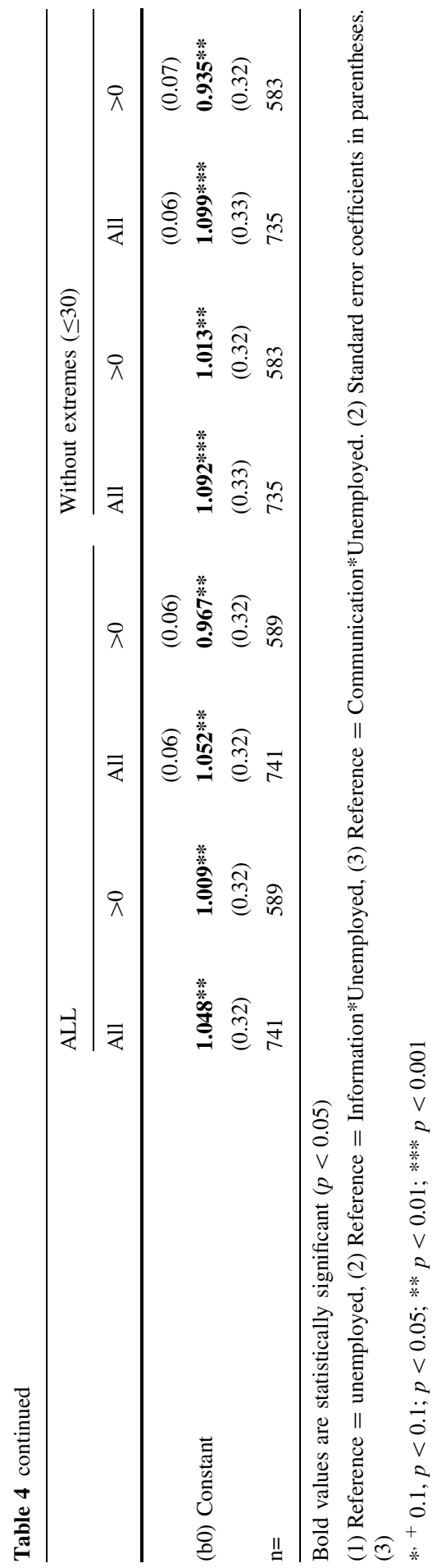




\section{Conclusion and discussion}

The results of our study confirmed that MOOCs were a well-accepted alternative for unemployed people with a higher educational level and those workers who did not received support for professional development. Unemployed people looking for a job may be more motivated to re/up skill than workers because they need up-to-date skills in order to increase their chances of (re)enter in the labour market. This result was consistent with the findings presented elsewhere (Castaño-Muñoz et al. 2016) that showed how in Spain specifically, the unemployment rate $^{2}$ for individuals with higher education was $14 \%$ in the first quarter of $2015^{3}$ and double (29\%) among comparable MOOC learners.

On the other hand, lack of employer support for professional development was usually associated to low level responsibility or routine jobs (Grund and Martin 2010) where there was no need for high level skills. Therefore, workers who are not supported by their employers were possibly motivated to take MOOCs in order to substitute the lack of training from their employers and to increase their chances of moving to a better job, which possibly would match better with the typically high educational level of MOOC learners. In addition, MOOCs flexibility, and openness in time and entry point make it easier to overcome the difficulties of combining it with a job context in which professional development is not supported.

Interestingly, employees with employer support were less likely to participate in MOOCs. Our analysis suggests that these learners spent more time on other professional development activities. Perhaps these workers were working in high level positions jobs where traditional training was supported by the company. This could have caused them to enroll on relatively few MOOCs for their lifelong learning activities.

However, workers with high levels of digital interaction skills who were supported by the employer chose to participate in MOOCs more often than those with lower levels, who opted for traditional training. Those workers are in an ideal situation since they are able to benefit of the MOOC-world and the traditional training world, maximizing their possibilities of training.

Overall, for workers in Europe to benefit from open education and MOOCs, it is essential that they have a high level of digital skills. Enhancing digital skills, and especially digital interaction skills, can reduce training costs and make education more flexible. This finding showed that employers can also invest in the development of digital skills of their employees to equip them with the necessary requirement to be active learners in an open education context.

Currently some MOOC providers are emphasizing the offer of professional development and professionalization training. If the current trend continues, more research is needed to see if MOOCs are recognized by companies as quality and reliable courses which can partially replace traditional lifelong learning and professional development formats with more flexible ones. At present they are often not recognized as formal education and identity recognition continues to be an issue.

\footnotetext{
${ }^{2}$ Defined as the number of people unemployed as a percentage of the active population.

3 Source: Instituto Nacional de Estadística.
} 
It also remains to be seen whether MOOCs can integrate tracks for learners with different preferences (Kalz and Specht 2013). Flexible recognition options of activities in open education are another important research and policy challenge to address the current barriers for lifelong learning and the potential to address them with new technologies (Kalz 2015).

The result of this study have the following limitations. Most of the participants came from Spain and it needs to be confirmed in the future if the relationships found can also be replicated in a more diverse set of MOOCs stemming from different countries. Specific characteristics such as the high unemployment rate in Spain might have biased some of the results. Due to a potential survival bias, MOOC participants who participate in online-surveys do not represent the whole population of MOOC participants. However, survey respondents could also be seen as a tool for filtering "active" participants (Evans et al. 2016). Nonetheless, the findings of the study remain valid beyond these limitations.

Acknowledgments This work has been partially funded by a tender (JRC/SVQ/2013/J.3/0035/NC) of the European Commission's Institute for Prospective Technological Studies (IPTS).

\section{Compliance with ethical standards}

\section{Conflict of interest None.}

Informed consent Participants to this research have declared their informed consent.

Open Access This article is distributed under the terms of the Creative Commons Attribution 4.0 International License (http://creativecommons.org/licenses/by/4.0/), which permits unrestricted use, distribution, and reproduction in any medium, provided you give appropriate credit to the original author(s) and the source, provide a link to the Creative Commons license, and indicate if changes were made.

\section{References}

Bernard, R. M., Abrami, P. C., Borokhovski, E., Wade, C. A., Tamim, R. M., Surkes, M. A., et al. (2009). A meta-analysis of three types of interaction treatments in distance education. Review of Educational Research, 79(3), 1243-1289. doi:10.3102/0034654309333844.

Blanden, J., Buscha, F., Sturgis, P., \& Urwin, P. (2012). Measuring the earnings returns to lifelong learning in the UK. Economics of Education Review, 31, 501-514.

Card, D., Kluve, J., \& Weber, A. (2010). Active labour market policy evaluations: A meta-analysis. Economic Journal, 120, F452-F477.

Castaño-Muñoz, J., Duart, J. M., \& Sancho-Vinuesa, T. (2014). The Internet in face-to-face higher education: Can interactive learning improve academic achievement? British Journal of Educational Technology, 45(1), 149-159.

Castaño-Muñoz, J., Punie, Y., \& Inamorato, A. (2016). MOOCs in Europe: Evidence from pilot surveys with universities and MOOC learners, JRC policy brief. Retrieved from: https://ec.europa.eu/jrc/ sites/jrcsh/files/JRC\%20brief\%20MOOCs_JRC101956.pdf

Castaño-Muñoz, J., Redecker, C., Vuorikari, R., \& Punie, Y. (2013). Open Education 2030: planning the future of adult learning in Europe. Open Learning, 28 (3). Retrieved from: http://www.tandfonline. com/doi/full/10.1080/02680513.2013.871199

Christensen, G., Steinmetz, A., Alcorn, B., Bennett, A., Woods, D., \& Emanuel, E. J. (2013). The MOOC phenomenon: Who takes massive open online courses and why? University of Pennsylvania. Retrieved from: http://papers.ssrn.com/sol3/papers.cfm?abstract_id=2350964 
European Commission. (2011). European agenda for adult learning and recent policy developments (Council resolution setting out a renewed European agenda for adult learning). Retrieved from http://ec.europa.eu/education/adult/agenda_en.htm

Evans, J. B., Baker, R. B., \& Dee, T. (2016). Persistence patterns in massive open online courses (MOOCs). The Journal of Higher Education, 87(2), 206-242.

Falconer, I., McGill, L., Littlejohn, A., \& Boursinou, E. (2013). Overview and analysis of practices with open educational resources in adult education in Europe (OER4Adults). JRC-IPTS, European Commission. Luxembourg: Publications Office of the European Union. Retrieved from http:// ftp.jrc.es/EURdoc/JRC85471.pdf

Fishbein, M., \& Ajzen, I. (2010). Predicting and changing behavior: The reasoned action approach. New York: Psychology Press.

Glass, C. R., Shiokawa-Baklan, M. S., \& Saltarelli, A. J. (2016). Who takes MOOCs? New directions for Institutional Research, 167. Retrieved from: http://onlinelibrary.wiley.com/doi/10.1002/ir.20153/ full

Grund, C., \& Martin, J. (2010). Determinants of further training: Evidence from Germany. IZA discussion Paper 5315. Retrieved from: http://ftp.iza.org/dp5315.pdf

Hällsten, M. (2012). Is it ever too late to study? The economic returns on late tertiary degrees in Sweden. Economics of Education Review, 31(1), 179-194. doi:10.1016/j.econedurev.2011.11.001.

Hayes, A. F. (2013). Introduction to mediation, moderation, and conditional process analysis: $A$ regression-based approach. New York: The Guilford Press.

Heckman, J., \& Smith, J. (1999). The pre-programme earnings dip and the determinants of participation in a social programme implications for simple programme evaluation strategies. Economic Journal, 109, 1-73.

Ho, A. D., Chuang, I., Reich, J., Coleman, C., Whitehill, J., Northcutt, C., Williams, J. J., Hansen, J., Lopez, G., \& Petersen, R. (2015). HarvardX and MITx: Two years of open online courses (HarvardX Working Paper No. 10). Retrieved from: http://dspace.mit.edu/bitstream/handle/1721.1/ 96825/SSRN-id2586847.pdf

Jenkins, A., Vignoles, A., Wolf, A., \& Galindo-Rueda, F. (2002). The determinants and effects of lifelong learning. Centre for the Economics of Education, London School of Economics and Political Science.

Jepsen, C., \& Montgomery, M. (2012). Back to school: An application of human capital theory for mature workers. Economics of Education Review, 31(1), 168-178. doi:10.1016/j.econedurev.2011.10.005.

Kalz, M. (2015). Lifelong learning and its support with new technologies. In J. D. Wright (Ed.), International encyclopedia of the social and behavioral sciences (Vol. 14, pp. 93-99). Oxford: Elsevier. doi:10.1016/B978-0-08-097086-8.92006-3.

Kalz, M., Kreijns, K., Walhout, J., Castaño-Munoz, J., Espasa, A., \& Tovar, E. (2015). Setting-up a European cross-provider data collection on open online courses. The International Review of Research in Open and Distributed Learning (IRRODL)., 16(6), 62-77.

Kalz, M., \& Specht, M. (2013). If MOOCS are the answer, did we ask the right questions? Implications for the design of large-scale online-courses. Working paper 2013/25. Maastricht School of Management, Maastricht.

Laal, M., \& Salamati, P. (2011). Lifelong learning; Why do we need it? Procedia- Social and Behavior Sciences, 31, 399-403.

Milligan, C., \& Littlejohn, A. (2014). Supporting Professional Learning in a Massive Open Online Course. The International Review of Research in Open and Distributed Learning (IRRODL).15(5). 197-213.

Radford, A. W., Robles, J., Cataylo, S., Horn, L., Thornton, J., \& Whitfield, K. (2014). The employer potential of MOOCs: A mixed-methods study of human resources professionals' thinking on MOOCs. The International Review of Research in Open and Distributed Learning (IRRODL)., 15(5), 1-25.

Ryan, R., \& Deci, E. (2000). Self-determination theory and the facilitation of intrinsic motivation, social development, and well-being. American Psychologist, 55, 68-78.

Schuetze, H., \& Slowey, M. (2002). Participation and exclusion: A comparative analysis of nontraditional students and lifelong learners in higher education. Higher Education, 44, 309-327.

UNESCO (2006). International Standard Classification of Education: ISCED 1997. Retrieved from http:// www.uis.unesco.org/Library/Documents/isced97-en.pdf 
Zhenghao, Z., Alcorn, B., Christensen, G., Eriksson, N., Koller, D., \& Emanuel, E. J. (2015). Who's benefiting from MOOCs, and why? Harvard Business Review, 25(Sept), Retrieved from https://hbr. org/2015/09/whos-benefiting-from-moocs-and-why\#.

Jonatan Castaño-Muñoz is researcher at the European Commission Joint Research Centre, Unit Human Capital and Employment. His research is focused on the socioeconomic implications of the modernisation of (higer) education and the use of e-learning, open education and MOOCs in higher education and lifelong learning.

Karel Kreijns is associate professor at the Welten Institute of the Open University of the Netherlands. His primary research interest are computer-supported collaborative learning (CSCL), the application of Self-Determination Theory, the I-Change model, and the Reasoned Action Approach on teachers' use of technology/Open Educational resources, enrolling in MOOCs, and teachers' professional development activities (e.g., innovative behavior, action research, 21st century skills).

Marco Kalz is Professor of Open Education at the Open University of the Netherlands. In his research he is focusing on dismantling barriers for participation in lifelong learning via digital technologies. He is currently coordinating several national and international research projects on open education.

Yves Punie is senior scientist at the European Commission Joint Research Centre in Seville, Unit Human Capital and Employment. He is leading its research and policy activities on "ICT for Learning and Skills". The research covers three main interrelated research strands, across all educational sectors: Open Education and OER, Innovating Learning and Teaching and Key Competences and 21st century skills. 